ГОДИШНИК

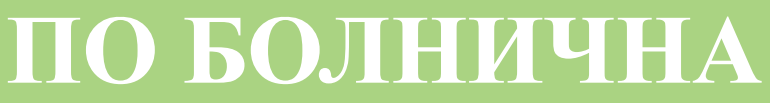
ФАРМАЦИЯ

\author{
Year 2017, volume 3, number 1 \\ ANNUAL \\ FOR HOSPITAL \\ PHARMACY
}

ISSN: $2367-8763$ ПРОФЕСИОНАЛНА
ОРРАНИЗЦИЯ НА
БОЛНИЧНИТЕ
ФАРМАЦЕВТИ
В БЪЛГАРИЯ

Официално издание на ПРОФЕСИОНАЛНАТА ОРГАНИЗАЦИЯ НА БОЛНИЧНИТЕ ФАРМАЦЕВТИ
Official publication of THE PROFESSIONAL ORGANIZATION OF HOSPITAL PHARMACISTS IN BULGARIA 


\section{ГЛАВЕН РЕДАКТОР}

доц. маг. фарм. Евгени Григоров, дм

\section{РЕДАКЦИОННА КОЛЕГИЯ}

проф. Златка Димитрова, дфн

проф. Илко Гетов, дф

проф. Георги Момеков, дф

доц. Асена Стоименова, дф

доц. Крум Кафеджийски, дф

доц. д-р Атанас Кундурджиев, дм

маг. фарм. Велина Григорова

\section{EDITOR IN CHIEF}

assoc. prof. Evgeni Grigorov, MScPharm, PhD

\section{EDITORIAL BOARD}

prof. Zlatka Dimitrova, MScPharm, DSc

prof. Ilko Getov, MScPharm, PhD

prof. Georgi Momekov, MScPharm, PhD

assoc. prof. Assena Stoimenova, MScPharm, $\mathrm{PhD}$

assoc. prof. Krum Kafedjiiski, MScPharm, $\mathrm{PhD}$

assoc. prof. Atanas Koundurdjiev, MD, PhD

Velina Grigorova, MScPharm

$\Phi$

\section{УКАЗАНИЯ ЗА АВТОРИТЕ}

Материалите се отпечатват на български език.

В списанието се публикуват: Научни статии (до 12 стр.), Обзори (до 12 стр.), Дискусия (до 3 стр.), Позиции (до 2 стр.), Мнения (до 1 стр.), Представяне на нови книги или софтуер (до 1 стр.)

Подаване на ръкописите се извършва единствено в електронен вид (на електронна поща ohpb_us@ googlegroups.com или на $\mathrm{CD}$ в офиса на редакцията).

\section{Изисквания към ръкописа:}

$\checkmark$ Заглавие, имена на авторите и месторабота по време на изготвяне на материала на български и английски език

$\checkmark$ Име и пълен адрес на кореспондиращия автор, телефон, електронна поща

$\checkmark$ Резюме: За научни статии се подготвя резюме със следната структура и подзаглавия: Въведение, Цел, Методи, Резултати и Заключение. При материали без структура (например, методологични материали) се допускат резюмета, неструктурирани по горния начин. Резюмето трябва да съдържа не повече от 250 думи и трябва да е на български и на английски език.

$\checkmark \quad$ Ключови думи: Представят се след резюмето на български и на английски език.

Файловете на ръкописа се подават във формат на Microsoft Word. Форматът на страниците трябва да бъде A4 с полета от 2,5 cm от всички страни, шрифтьт 12-point Times New Roman с 1 интервал меж-

ду редовете. Текстьт се подравнява само от ляво.

Местата на таблиците и фигурите се отбелязват в текста с поредния им номер и обозначението „Таблица“ и „Фиг.“ (напр. „Таблица 1“ или „Фиг. 1“). Всяка таблица и фигура се представя в отделен файл в оригиналния файлов формат (снимките трябва да бъдат в графичен формат - jpg, png, tif), като имената им трябва да съответстват на обозначенията в текста. Обяснителният текст на всяка фигура или таблица се поставя в текста към обозначението ѝ. Приемат се само черно-бели фигури (диаграми, схеми и снимки). Максималният брой на фигурите е десет. Всички снимки трябва да бъдат сканирани като grayscale в 300 DPI. Те трябва да са достатьчно контрастни и с размер минимум 8,4 см широчина (1 колона) или 17,5 см в широчина (2 колони). Диаграмите трябва да се представят в отделни файлове в оригиналния файлов формат (напр. xls).

Библиография: Цитираните източници се подреждат и описват непосредствено след основния текст. В текста номерът на цитирания източник се поставя в скоби ( ). 


\section{СЪДЪРЖАНИЕ}

ПРОУЧВАНЕ РОЛЯТА НА КЛИНИЧНИЯ ФАРМАЦЕВТ ПРИ ПРИГОТВЯНЕ

И ПРИЛАГАНЕ НА РАДИОФАРМАЦЕВТИЦИ

Станислава Йорданова, Илко Гетов

ЕЛЕКТРОННАТА ПЛАТФОРМА ЗА ЗАКУПУВАНЕ НА ЛЕКАРСТВА ЗА БОЛНИЦИТЕ НОВО ПРЕДИЗВИКАТЕЛСТВО ПРЕД ФАРМАЦЕВТИТЕ

Светлана Гълева, Орлин Недев, Евгени Григоров 13

ОЦЕНКА НА ЗДРАВНАТА ТЕХНОЛОГИЯ IXЕКIZUМАВ ЗА ЛЕЧЕНИЕ

НА ПЛАКАТЕН ПСОРИАЗИС В БЪЛГАРИЯ

Дима Цанова, Надя Велева, Тони Веков, Живко Колев, Евгени Григоров $-19$

КОЖЕН Т-КЛЕТЬЧЕН ЛИМФОМ (СТСL). ТЕРАПЕВТИЧНИ ОПЦИИ

Мая Йотова, Калоян Калоянов, Калоян Георгиев $-26$

НУТРИГЕНЕТИКА - ЕДНО НОВО НАПРАВЛЕНИЕ В МЕДИЦИНАТА

Олга Антонова, Боряна Герасимова, Валентина Белчева, Драга Тончева $-30$

ТЕРАПЕВТИЧНИ СТРАТЕГИИ ЗА НАМАЛЯВАНЕ НА СЪРДЕЧНО-СЪДОВИЯ РИСК ПРИ ПАЦИЕНТ С ВЪЗПАЛИТЕЛНИ СТАВНИ ЗАБОЛЯВАНИЯ

Иван Груев, Цветомир Делийски, Живко Колев $-35$

\section{Адрес на редакцията:}

списание "Годишник по болнична фармация" Официално издание на ПОБФБ

София, 1040

ИНТЕРПРЕД - СТЦ

Бул."Драган Цанков" 36, офис Б 602 ет.6 evgeni.grigorov@mu-varna.bg
Университетско издателство Медицински университет "Проф. д-р П. Стоянов" - Варна Варна 9002, ул. Марин Дринов 55 тел.:+35952677112

e-mail: press@mu-varna.bg Предпечат: Емилия Йорданова 


\section{CONTENTS}

STUDY OF THE CLINICAL PHARMACIST ROLE IN PREPARATION AND APPLICATION OF RADIOPHARMACEUTICALS

Stanislava Yordanova, Ilko Getov 5

ELECTRONIC PLATFORM FOR PURCHASING MEDICINES FOR HOSPITALS - A NEW CHALLENGE FOR THE PHARMACISTS

Svetlana Galeva, Orlin Nedev, Evgeni Grigorov 13

HEALTH TECHNOLOGY ASSESSMENT OF IXEKIZUMAB FOR TREATMENT

OF PLAQUE PSORIASIS IN BULGARIA

Dima Tsanova, Nadia Veleva, Toni Vekov, Jivko Kolev, Evgeni Grigorov 19

CUTANEOUS T-CELL LYMPHOMA (CTCL). THERAPEUTIC OPTIONS

Maya Yotova, Kaloyan Kaloyanov, Kaloyan Georgiev 26

NUTRIGENETICS - ONE NEW DIRECTION IN MEDICINE

Olga Antonova, Boryana Gerasimova, Valentina Belcheva, Draga Toncheva$-30$

THERAPEUTIC STRATEGIES FOR REDUCTION OF THE CARDIOVASCULAR RISK IN PATIENTS WITH INFLAMMATORY JOINT DISEASES

Ivan Gruev, Tzvetomir Delyiski, Jivko Kolev $-35$

CURRICULUM FOR POST-GRADUATE SPECIALIZATON ON HOSPITAL PHARMACY 42

Editorial office address:

Journal „Annual for hospital pharmacy”

Official publication of POHPB

Sofia, 1040

Interpred - WTC

"Dragan Tsankov" 36, blvd., office B 602, floor 6

evgeni.grigorov@mu-varna.bg
Varna Medical University Press

55 Marin Drinov Str, Varna, 9002

phone.:+35952 677112

e-mail: press@mu-varna.bg

Preprint: Emilia Yordanova 